\title{
HIGH PRECISION FULLY INTEGRATED AIRBORNE DIGITAL MAPPING SYSTEMS - STATE OF THE ART AND PERFORMANCE ANALYSIS
}

\author{
M.M.R. Mostafa ${ }^{1,}$ *, J. Hutton ${ }^{2}$, S. Sobol ${ }^{2}$, L.Viveros ${ }^{3}$, S. Cooper ${ }^{3}$, Y. Raizman ${ }^{3}$ \\ ${ }^{1}$ Navmatica Corporation, 4711 Yonge Street, 10 $10^{\text {th }}$ Floor, Toronto, Ontario, Canada M2N 6K8 - mohamed.mostafa@navmatica.com \\ ${ }^{2}$ Applanix Corporation, 85 Leek Cr., Richmond Hill, Ontario, Canada L4B 3B3 - (jhutton, ssobol)@ Applanix.com \\ ${ }^{3}$ Phase One A/S, Roskildevej 39, 2000 Frederiksberg, Denmark - (ldv, sco, yra)@phaseone.com
}

Commission VI, WG VI/4

KEY WORDS: Camera, Integration, Inertial, GNSS, Calibration, Airborne Mapping, Direct Georeferencing

\begin{abstract}
:
This paper introduces the Phase One Aerial System 150, a next generation fully integrated fully digital aerial camera system with one single digital camera head and lens which almost matches the perfect geometry of a film camera for all airborne mapping applications. It is the first true replacement for the simplicity, geometry and efficiency established by film cameras for traditional airborne mapping. Several test flights were planned to be flown with the Phase One Aerial System 150 over the Greater Denver Area, Colorado, U.S.A. during the Winter of 2020. Two lenses are planned to be used, namely: 1) $50 \mathrm{~mm}$ lens for wide coverage and a geometry closest to that of a film camera which is suitable for most mapping applications, and 2) $90 \mathrm{~mm}$ lens which provides a higher resolution (smaller GSD) and a narrower field of view which is suitable for applications where less building lean might be required. Multiple flight altitudes are flown in order to end up with a GSD of $10 \mathrm{~cm}$, and $20 \mathrm{~cm}$, respectively. One dual-altitude flight was planned to characterize and calibrate the integrated system including camera in-flight calibration and camera/IMU boresight calibration. The remaining flights are planned to be used to validate system accuracy and productivity as well as the mapping product accuracy. Due to the Covid-19 pandemic and poor weather, only one full dual-altitude light has been flown. Therefore, system calibration, assessment, and validation are done using this single test flight. The remainder of the test flights intended for map production evaluation and accuracy assessment will be flown during the Spring of 2020, which results will be shared with the ISPRS audience during the congress presentations.
\end{abstract}

\section{INTRODUCTION}

Traditionally, airborne mapping was done using large format airborne film cameras. These cameras continuously served the airborne mapping profession for over 5 decades ever since their inception after WWII. Over the years, they evolved to be meticulously designed, engineered and most importantly built with the lens geometry to produce high precision mapping products. Mapping Standards have been well established around the globe for federal, state, and municipal governments with these cameras' capabilities and limitations in mind. The knowhow of building a high-quality airborne film camera was proprietary, yet the knowledge base of using them and extracting excellent mapping products was shared around the world through conferences and technical/business meetings. By the late nineties, there were about a thousand operational film cameras around the globe.

In the early 2000's, airborne camera manufacturers heavily invested in replacing their film cameras with digital. The first large format airborne digital camera was an ADS40 line scanner built by Leica in 2001. This was followed a few years later by offerings by Intergraph (c.f., Hinz et al, 2001) and Vexcel (c.f., Leberl, 2004) which were built by combining a group of small or medium format cameras into one box. A multi-camera system normally produced a few images almost simultaneously which were stitched together to produce a single yet larger image in post-processing mode. While quite effective, and with the benefit of being able to produce four band imagery (R, G, B, NIR), the systems tend to be large, complex and expensive due to the duplication of components. Most large format digital cameras have continued to evolve around this principle until today.

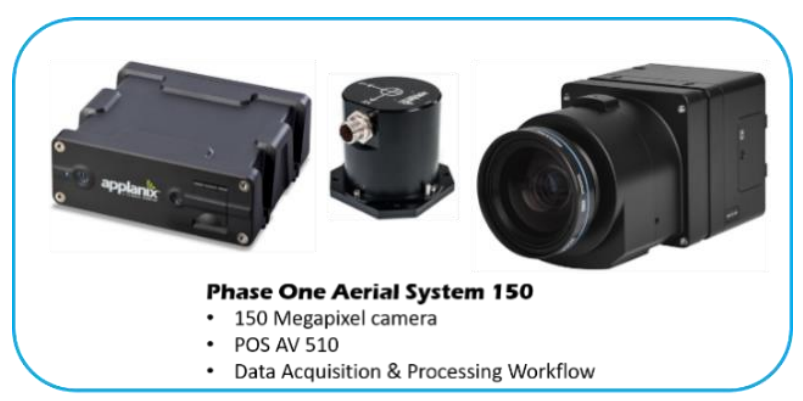

Figure 1: Phase One Aerial System 150

This paper introduces the Phase One Aerial System 150 (PAS 150), a next generation fully integrated fully digital aerial camera system with built-in Direct Georeferencing and a single digital camera head, Figure 1.

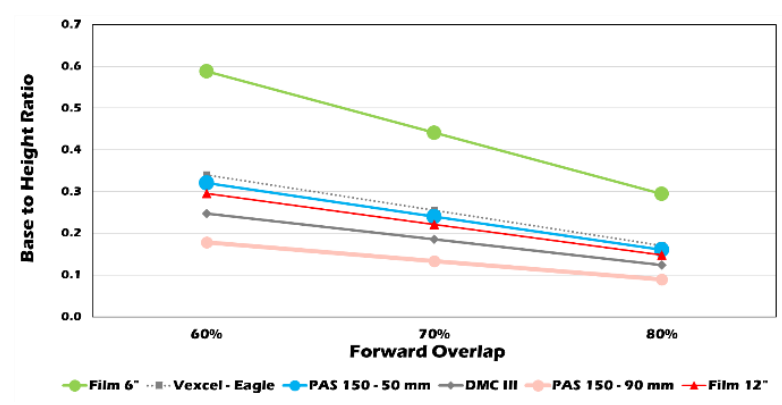

Figure 2: Base to Height Ratio for Commercial Systems

\footnotetext{
* Corresponding author
} 
The PAS 150 is the first true cost-effective replacement for the simplicity, geometry and efficiency established by film cameras for traditional airborne mapping. The system comprises a 150 mega pixel RGB digital camera integrated with an inertiallyaided GNSS system and a full workflow for mission planning, data acquisition, data processing, calibration, and quality control. It has the geometry and precision of a traditional film camera, but with superior digital image resolution and quality in addition to an all-digital workflow. With a better Base to Height Ratio than that of a traditional film camera with $300 \mathrm{~mm}$ lens, it is competitive with other commercial airborne systems for stereo mapping (Figure 2).

Including an embedded Applanix AP+ OEM Direct Georeferencing system, it is a complete and compact solution that is metric and directly georeferenced. The system has been designed and engineered to be flown by any manned platform for any number of hours to map districts, cities, states, and countries from any altitude in any $3^{\text {rd }}$ party map production environment. It acquires high quality digital images perfectly synchronized with the built-in inertially-aided GNSS sensors that measure the camera motion in six degrees of freedom at $200 \mathrm{~Hz}$.
This allows for georeferencing each captured pixel in near real time or in post-processing modes which leads to producing a variety of mapping products without the need for ground control. Six test flights were planned to be flown with the Phase One Aerial System 150 over the Greater Denver Area, Colorado, U.S.A. during the Winter of 2020. Two lenses are planned to be used, namely: 1) $50 \mathrm{~mm}$ lens for wide coverage and a geometry closest to that of a film camera which is suitable for most mapping applications, and 2) $90 \mathrm{~mm}$ lens which provides a higher resolution (smaller GSD) and a narrower field of view which is suitable for applications where less building lean might be required. Multiple flight altitudes are flown in order to end up with a GSD of $10 \mathrm{~cm}$, and $20 \mathrm{~cm}$, respectively. However, due to the Covid-19 pandemic and poor weather, only one flight has been flown including 2 flight altitudes.

Therefore, system characterisation, calibration, assessment, and validation are done using this single test flight. The remainder of the test flights intended for map production evaluation and accuracy assessment will be flown during the Spring of 2020, which results will be shared with the ISPRS audience during the ISPRS Congress presentations.

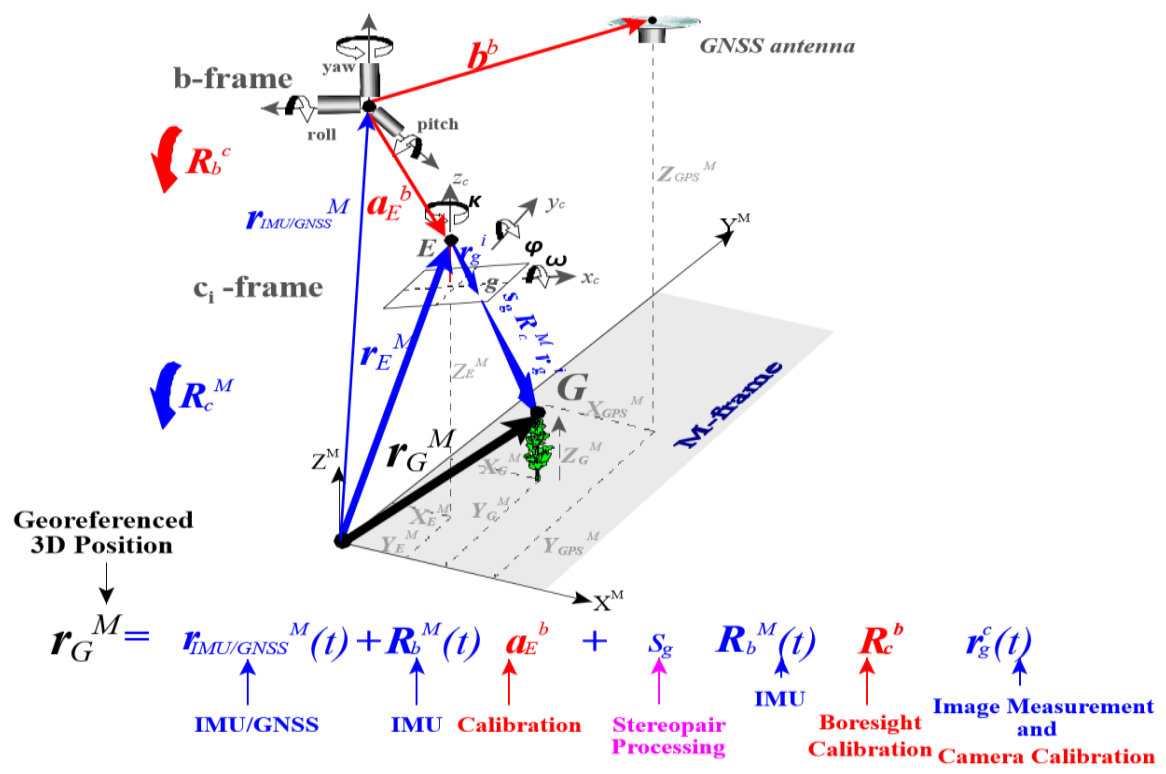

Figure 3: Direct Georeferencing (Mostafa, et al., 1997)

\subsection{Direct Georeferencing}

Direct Georeferencing (DG) is the process of computing the ground coordinates for any ground point that appears in an airborne image using inertial/GNSS integrated systems, as shown in Figure 3. DG is a scientific concept that is applicable to any airborne or terrestrial camera once integrated with GNSS/Inertial system. Schwarz et al, 1993 pioneered DG in the Academia using Differential GPS integrated with Inertial Navigation Systems (INS) for airborne and terrestrial applications. During the 1990s, the university of Calgary and Ohio State University researched the use of Direct Georeferencing when integrated with many airborne sensors including film cameras (c.f., Škaloud, et al, 1996) or single digital cameras (c.f., Mostafa et al, 1997) or multiple digital cameras (c.f., Mostafa and Schwarz, 2000).

Simultaneously, in the commercial environment, Reid, et al (1998) introduced the first professional-grade commercial product to the airborne mapping profession using an IMUintegrated DGPS (c.f., Hutton et al, 1997).
Scherzinger, 1997 introduced commercial grade post-processing softwares that integrated GNSS/inertial data for high precision applications used in the airborne mapping profession.

In 2001, the University of Hannover led a European effort to assess the validity, productivity, applicability, and accuracy of Direct Georeferencing using multiple real world data sets acquired by several European airborne photogrammetric professional service providers in a true map production environment (c.f. Heipke et al, 2001). The results of this effort proved the superiority of DG to the traditional GCP-based aerotriangulation (AT) technique. These results were shared in the airborne mapping profession around the globe which led airborne mappers to use Direct Georeferencing in their daily mapping services due to the fact that DG allows for acquiring any airborne image projects of any geometric configuration for map production in any applications including corridor and area mapping with significant economical and operational advantages. Figure 3 illustrates the DG concept where all measurable quantities are color-coded in blue while calibration parameters are color-coded in Red. 


\section{DATA DESCRIPTION}

Initially, six test flights were planned to be completed before writing this paper. However, due to the Covid-19 Pandemic, only one test flight was acquired. The remainder of the test flights will be done during the Spring/Summer of 2020 the results of which will be presented during the ISPRS Congress in 2021.

\subsection{Test Flight Description}

The Phase One Aerial System 150 was flown over a test field in Louisville, Colorado, USA, where Sixteen Ground Control Points (GCPs) have been established, as shown in Figure 4. DualAltitude flights have been proven successful in providing high precision simultaneous camera and boresight calibration (c.f., Mostafa et al, 1997, Mostafa, 2004, Ip et al, 2006 and Casella et al, 2006.) As a result a Dual-Altitude flight was flown which resulted in a Ground Sample Distance (GSD) of $10 \mathrm{~cm}$ and 20 $\mathrm{cm}$, respectively as shown in Figure 5. The lower flight altitude included four North-South flight lines, while the higher flight altitude included two East-West flight lines.

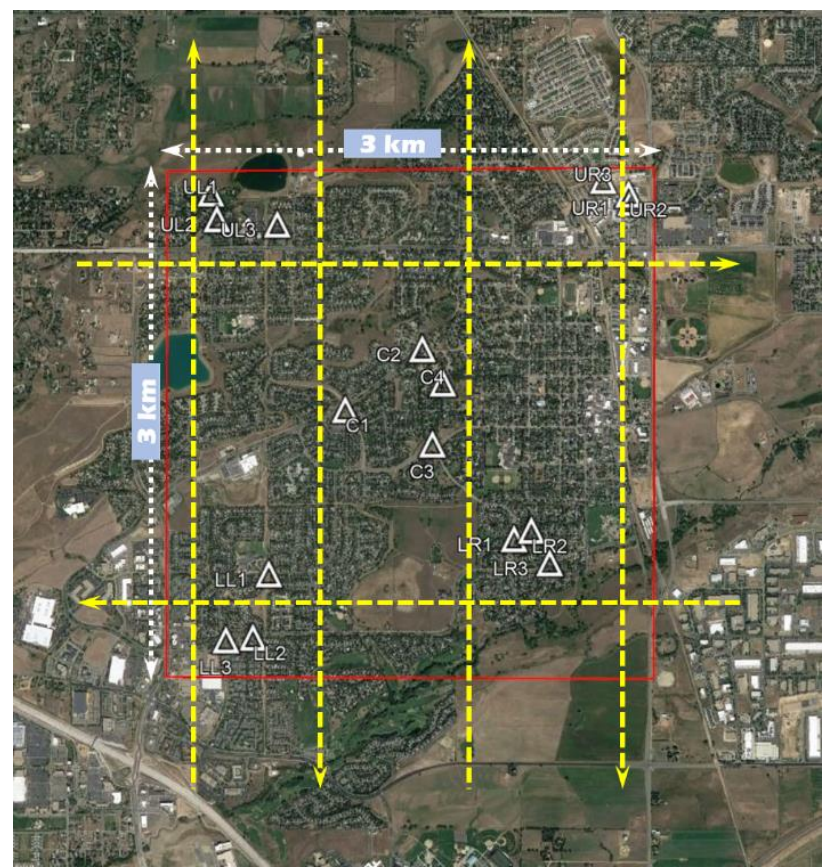

Figure 4: Test Flight Layout in Louisville, CO, USA

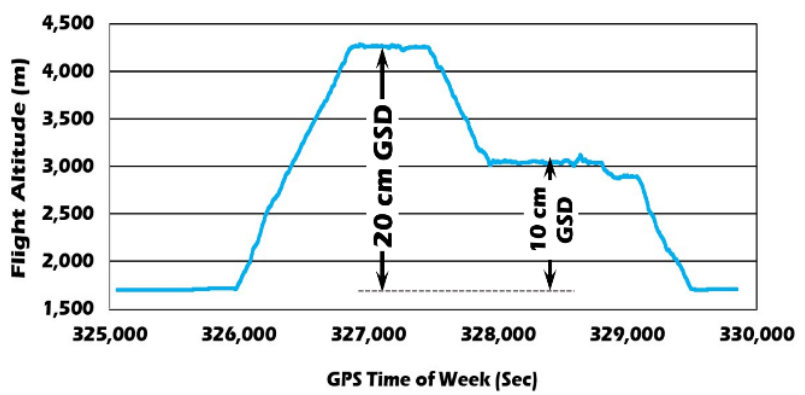

Figure 5: Dual-Altitude Flight and its associated GSD

The Phase One Aerial System 150 design avoided complexity and focused on simplicity to end up with a compact high precision reasonably priced camera.
As a result, by design, image motion compensation is not included in the camera. On the other hand, a typical airborne mapping error budget includes image measurement precision.

Therefore, image motion blur needs to be maintained within one pixel to end up with crisp imagery to enable high image measurement precision. Figure 6 illustrates image motion blur for different shutter speeds for a cruise speed of 130 knots. Figure 6 confirms that for a $1,000 \mathrm{~m}$ flight altitude or higher, image motion blur is sub-pixel in nature at 130 knots $(240 \mathrm{Km} / \mathrm{Hr})$ cruise speed for shutter speeds of $1 / 1000 \mathrm{sec}$ or faster. As a result, the desired $10 \mathrm{~cm}$ and $20 \mathrm{~cm}$ GSD are easily achievable with subpixel image motion blur.

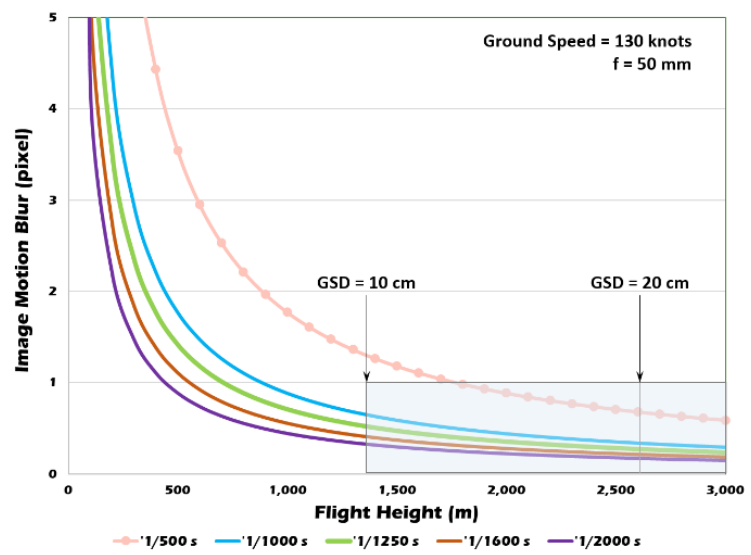

Figure 6: Image Motion Blur for a 130 Knots Cruise Speed

\subsection{The Dedicated Base Station}

In order to characterise, calibrate, and asses an integrated airborne mapping system, it is necessary to achieve high positioning accuracy of the aircraft GNSS antenna. Therefore, albeit the fact that it is convenient to use other high-quality alternatives, a dedicated base station has been identified as a necessary component of all test flights.

A Sitech permanent tracking SPS855 GNSS receiver has been used as the dedicated base station for all test flights. This receiver is one of an array of Trimble GNSS permanent tracking receivers mounted on the rooftop of Trimble Offices in Westminster, CO. Additionally, as shown at the beginning (before take-off) and at the end (after landing) of the baseline length plot shown in Figure 6 , this GNSS base station is less than $3 \mathrm{Km}$ away from the airport used for all test flight. Moreover, since the test field is close to the airport, the maximum baseline length did not exceed $22 \mathrm{Km}$ as shown in Figure 7.

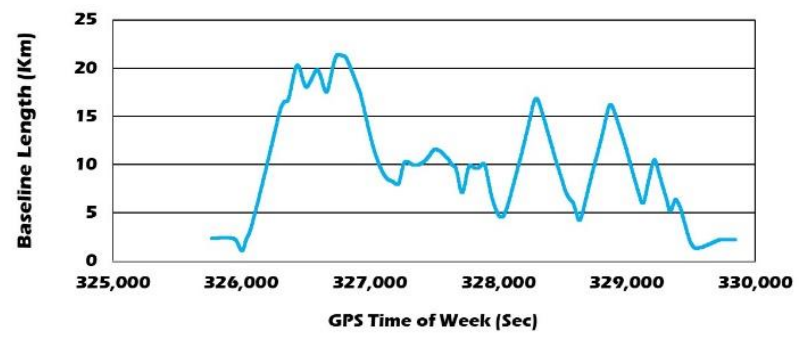

Figure 7: Baseline Length (Km) 


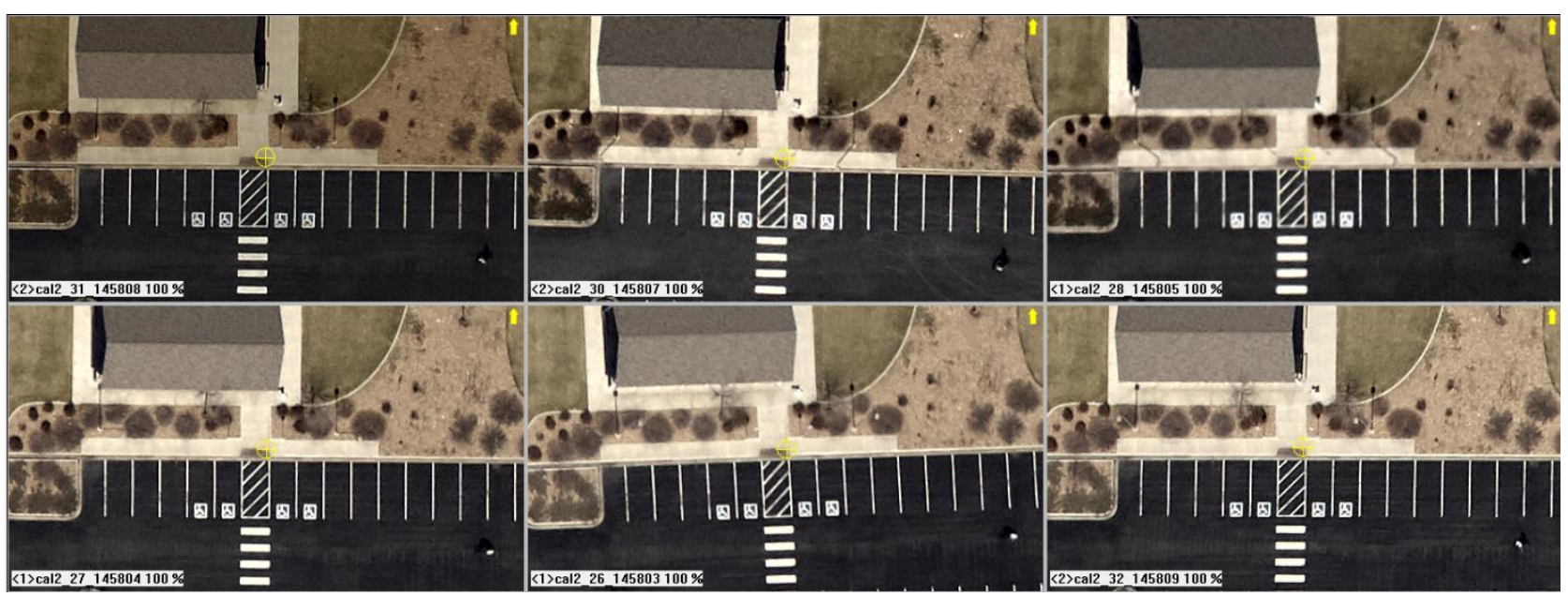

Figure 8: Check Point Automated Measurement in CalQC

\subsection{Ground Control and Check Points}

A total of sixteen GCPs were established in the test field in Louisville, CO, USA. Static GNSS observations of an average of 30 minutes were acquired for each GCP using 3 Trimble R8s GNSS receivers simultaneously.

The GCP GNSS data was processed in conjunction with five nearby CORS stations. This resulted in 178 GNSS baselines that were processed in a network adjustment environment.

The calculated standard deviation for the GCP coordinates as well as the SPS 855 base station coordinates was $2.5 \mathrm{~cm}$ in 3D. Therefore, the newly established GCP coordinates 3D accuracy is within $25 \%$ the smallest GSD of $10 \mathrm{~cm}$.

\section{DATA PROCESSING}

\subsection{Trajectory Data Processing}

The POSPac MMS GNSS-Aided inertial processing software package was used to process the trajectory data as shown in Figure 9.

The positioning and orientation accuracy of the camera photo centre as estimated by POSPac MMS are shown in Figure 10 and Figure 11, respectively. Additionally, four scenarios were used in POSPac MMS to process the trajectory data, using either:

- The dedicated SPS855 base station and pre-surveyed coordinates

- The dedicated SPS855 base station and coordinates surveyed in using the Trimble Centerpoint RTX service

- $\quad$ The Applanix Smartbase Post-processed Virtual Reference Station (VRS) module

- The POSPac Post-processed Trimble Centerpoint RTX (PPRTX) service for trajectory processing without base stations

As a result, four Smoothed Best Estimate Trajectory (SBET) files were produced using the abovementioned methods. The four trajectory files were compared. The RMS of the difference was well within the smallest GSD of $10 \mathrm{~cm}$. This confirms that the photo centre position was measured to an accuracy of better than one pixel using four different data post-processing techniques when using the POS AV 510 system to georeference the Phase One Aerial System 150.

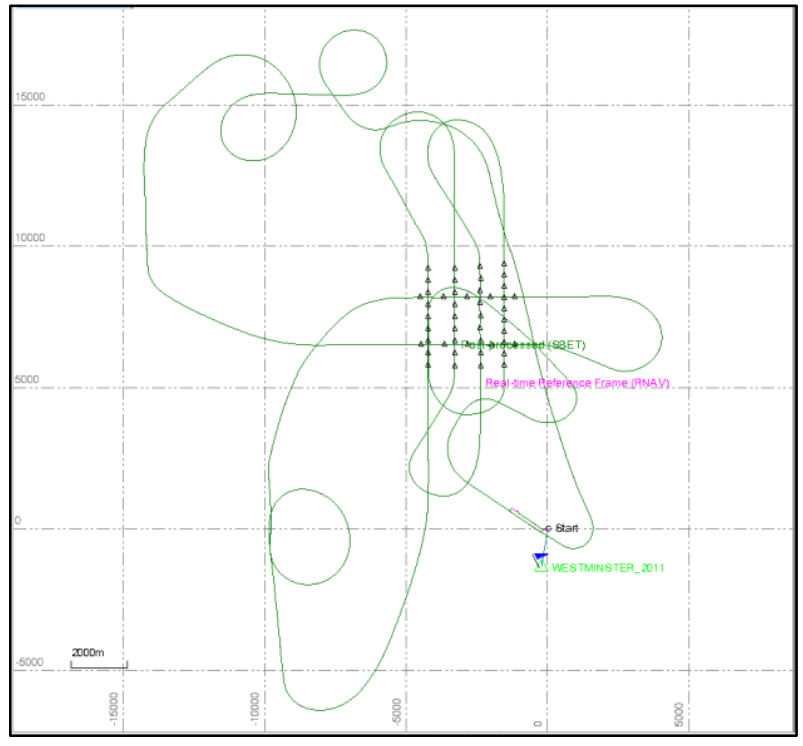

Figure 9: Test Flight Trajectory illustrating the N-S low-altitude flight lines and the E-W high-altitude flight lines

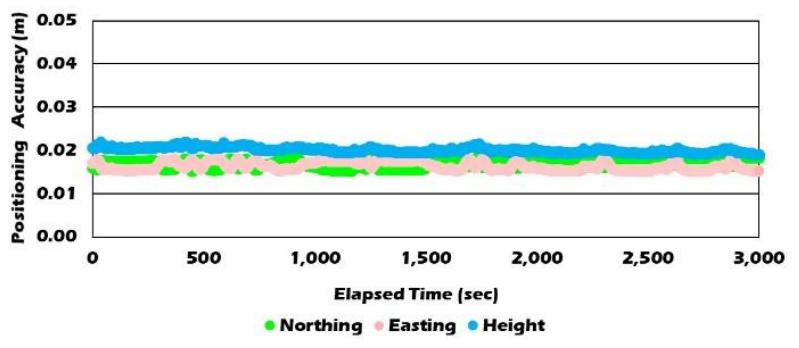

Figure 10: Flight Positioning Accuracy (m)

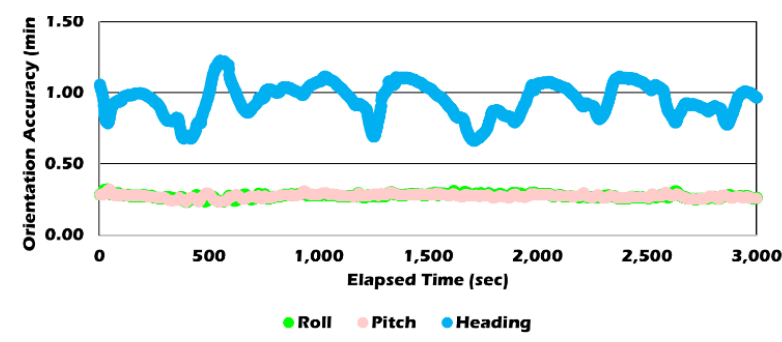

Figure 11: Flight Orientation Accuracy (minute) 


\subsection{Photogrammetric Data Processing}

The dual-altitude image data contains six flight lines, four of which have a $10 \mathrm{~cm}$ GSD while the two higher altitude flight lines have a $20 \mathrm{~cm}$ GSD.

Two processing sessions were done, namely:

\section{In-flight Calibration Session}

2. Accuracy Assessment Session

During the In-flight Calibration Session, the Inpho Photogrammetric software package was used to do the in-flight calibration for both camera interior orientation and boresight, where the following data streams were used:

- $\quad$ POS-measured Exterior Orientation parameters

- Dual-Altitude Imagery

- Factory camera calibration report

During the Accuracy Assessment Session, the following data streams were used:

- POS-measured Exterior Orientation parameters

- The lower altitude Imagery of $10 \mathrm{~cm}$ GSD.

- In-flight camera and boresight calibrated parameters

In other words, the camera and boresight calibration parameters obtained from the In-Flight Calibration Session were treated as error-free (held-fixed) during the Accuracy Assessment Session.

\section{RESULTS}

While the in-flight calibration converged and produced results, it was discovered that the image radiometric quality was suboptimal (due to clouds and shadows).

Hence it is suspected that the in-flight calibration of the camera interior orientation is not as accurate as it could be, and the accuracy assessment is thus only preliminary.

For the accuracy assessment, all GCPs were used as check points. The check point residuals are shown in Table 1 , where three scenarios are presented, namely:

- Corridor mapping using one strip of images

- Corridor mapping using two strips of images

- $\quad$ Area mapping using 4 strips of images

\begin{tabular}{clrrr}
\hline Application & Statistic & \multicolumn{1}{c}{$\begin{array}{c}\mathrm{dX} \\
(\mathrm{m})\end{array}$} & $\begin{array}{l}\mathrm{d} \\
(\mathrm{m})\end{array}$ & $\begin{array}{c}\mathrm{d} \\
(\mathrm{m})\end{array}$ \\
\hline \multirow{2}{*}{$\begin{array}{c}\text { Corridor } \\
\text { Mapping }\end{array}$} & Min & -0.49 & -0.47 & -0.89 \\
\cline { 2 - 5 } 1 Strip & Max & 0.39 & 0.45 & 0.68 \\
\cline { 2 - 5 } & Mean & -0.06 & -0.05 & -0.07 \\
\cline { 2 - 5 } & RMS & $\mathbf{0 . 1 7}$ & $\mathbf{0 . 1 9}$ & $\mathbf{0 . 3 8}$ \\
\hline \multirow{2}{*}{$\begin{array}{l}\text { Corridor } \\
\text { Mapping }\end{array}$} & Min & -0.41 & -0.46 & -0.85 \\
\cline { 2 - 5 } 2 Strips & Mean & 0.38 & 0.41 & 0.71 \\
\cline { 2 - 5 } & RMS & -0.02 & 0.00 & -0.09 \\
\hline \multirow{2}{*}{$\begin{array}{c}\text { Area } \\
\text { Mapping } \\
\text { 4 Strips }\end{array}$} & Min & -0.48 & -0.48 & -0.77 \\
\cline { 2 - 5 } & Max & 0.37 & 0.43 & 0.65 \\
\cline { 2 - 5 } & Mean & -0.04 & -0.05 & -0.06 \\
\cline { 2 - 5 } & RMS & $\mathbf{0 . 1 6}$ & $\mathbf{0 . 1 6}$ & $\mathbf{0 . 3 5}$ \\
\hline
\end{tabular}

Table 1: Check Point Residuals (m)

\section{CONCLUSIONS}

While only one flight out of a total of 6 was flown due to the Covid-19 pandemic and weather, the results from the single dual altitude flight show the Phase One Aerial System 150 integrated with the Applanix OEM POS AV 510 is a highly efficient, stable metric mapping solution.

Furthermore, a preliminary accuracy assessment using Direct Georeferencing shows it can achieve 2-pixel horizontal and 4pixel vertical accuracy for corridor and area mapping, all without the use of Ground Control Points.

\section{FUTURE WORK}

Future work will include flying five more flights which will be used to generate a more accurate in-flight calibration and for an independent accuracy assessment using corridor mapping imaging configuration as well as area mapping imaging configuration.

\section{ACKNOWLEDGEMENTS}

The authors would like to acknowledge the efforts made by Olivia Link of Phase One for her assistance with flight planning, Nilesh Gopal and Patrick Lasagna of Applanix for processing the Ground Control Point GNSS data, and Daniel Butvidas of Trimble Inc for the GCP data acquisition.

\section{REFERENCES}

Casella, V., K. Jacobsen, M.M.R. Mostafa, and M. Franzini, 2006. A European Project on Direct Georeferencing, Proceedings, ASPRS Annual conference, Reno, Nevada, May 15, 2006 .

Hinz A., Dörstel C, Heier H., 2001: DMC - The Digital Sensor Technology of Z/I-Imaging, Photogrammetric Week 2001, Stuttgart, Germany, Eds D. Fritsch / R. Spiller, Wichmann, Heidelberg

Heipke, C, Jacobsen, K, Wegmann, H, Andersen, O and Nilsen, B., 2000. Integrated Sensor Orientation-An OEEPE Test. International Archives of Photogrammetry and Remote Sensing, Vol. XXXIII, Amsterdam, 2000.

Hutton, J., Savina, T., and Lithopoulos, L., 1997. Photogrammetric Applications of Applanix's Position and Orientation System (POS). ASPRS/MAPPS Softcopy Conference, Arlington, Virginia, July 27 - 30.

Ip, A.W.L., N. El-Sheimy and M.M.R. Mostafa, 2007. Performance Analysis of Integrated Sensor Orientation, $P E \& R S$, 73(1): 89-97, 2007.

Ip, A.W.L., W. Dillane, A. Giannelia and M.M.R. Mostafa, 2006. Georeferencing of the UltraCam D Images - Boresight Calibration Results, Direct Georeferencing Column, PE\&RS, 72(1): 9, 2006.

Leberl, F., 2004. The Economic Sense of Fully Digital Aerial Sensing. Proceedings ASPRS Annual Conference, Denver, Colorado, USA, May 23-28

Mostafa, M.M.R., Roy, E., and Zhang, X., 2007. SmartBase ${ }^{\mathrm{TM}}$ an Efficient New Tool for Aircraft Positioning Using Continuously Operated Reference Stations for Mapping 
Applications. Proceedings, The American Society of Photogrammetry and Remote Sensing Fall Meeting, Ottawa, Canada, Oct 28 - Nov 1.

Mostafa, M.M.R., 2004. Airborne Testing of the DSS. Proceedings, IAPRS, Vol. XXXV, ISSN 1682-1750 (ISPRS XX ${ }^{\text {th }}$ Congress, Istanbul, Turkey, July 12-23, 2004).

Mostafa, M.M.R. and J. Hutton, 2001. Direct Positioning and Orientation Systems: How Do They Work? What is The Attainable Accuracy? Proceedings, The American Society of Photogrammetry and Remote Sensing Annual Meeting, St. Louis, MO, USA, April 23 - 27.

Mostafa, M.M.R. and K.P. Schwarz, 2000. A Multi-Sensor System for Airborne Image Capture and Georeferencing. PE\&RS, 66 (12): 1417-1424.

Mostafa, M.M.R., K.P. Schwarz, and P. Gong, 1997. A Fully Digital System for Airborne Mapping, Proceedings, Kinematic Integrated Systems - KIS97, Banff, Canada, June 3-6, pp. 463471.

Reid, D.B., E. Lithopoulos, and J. Hutton, 1998. Position and Orientation System for Direct Georeferencing (POS/DG), Proceedings, Institute of Navigation 54th Annual Meeting, Denver, Colorado, USA, June 1-3, pp. 445-449.

Schwarz, K.P., M.A. Chapman, M.E. Cannon and P. Gong, 1993. An Integrated INS/GPS Approach to The Georeferencing of Remotely Sensed Data, PE\&RS, 59(11): 1167-1674.

Škaloud, J., M. Cramer, and K.P. Schwarz, 1996. Exterior Orientation by Direct Measurement of Position and Attitude, International Archives of Photogrammetry and Remote Sensing, 31 (B3): 125-130.

Thurgood, J.D. and M. Gruber, 2004. Changed Rules in Aerial Photogrammetry. Proceedings ASPRS Annual Conference, Denver, Colorado, USA, May 23-28.

Scherzinger, B., 1997. A Position and Orientation PostProcessing Software Package for Inertial/GPS Integration (POSProc). Proceedings of the International Symposium on Kinematic Systems in Geodesy, Geomatics and Navigation (KISS 97), Banff, Canada, June 1997.

Ziemann, H., 1997: Comparing the Photogrammetric Performance of film-based aerial cameras and digital cameras. Proceedings: Photogrammetric Week '97, Eds. D. Fritsch/D. Hobbie, Wichmann, Heidelberg. 